\title{
Surgical Management of Adult Reducible Atlantoaxial Dislocation, Basilar Invagination and Chiari Malformation with Syringomyelia
}

\author{
Gong SHUHUI, Liu JIAGANG, Chen HAIFENG, Zhao Bo HAO, Huang Si QING \\ Sichuan University, West China Hospital, Department of Neurosurgery, China
}

\section{ABSTRACT}

AIM: To analyze retrospectively the surgical management of reducible atlantoaxial dislocation (AAD), basilar invagination (BI) and Chiari malformation (CHM) with syringomyelia through a single-stage posterior approach.

MATERIAL and METHODS: Forty-three patients with reducible AAD, BI and CHM with syringomyelia underwent surgery from January 2009 to January 2013. Intraoperative restoration followed by posterior decompression and plate-rod placement with occipital cortical screws and C2/C3 lateral mass cortical screws fixation devices were used in all patients. Results were recorded both pre- and postoperatively and these outcome measures included Nurick grading (NG) and radiology findings (atlantodental interval (ADI), space available for the spinal cord (SAC), interval between odontoid and Chamberlain's line (IOC), and the cervicomedullary angle (CMA)).

RESULTS: Forty (93\%) of the 43 patients were followed up. Thirty-six (90\%) patients' symptoms improved and four (10\%) stabilized. No patients became progressively worse. The difference between preoperative and postoperative Nurick grades was statistically significant. All patients achieved restoration, including thirty (75\%) patients had full restoration and ten (25\%) had part restoration. The size of syringomyelia was obviously decreased in $32(80 \%)$ patients and stable in $8(20 \%)$ patients. All radiology findings (ADI, IOC, SAC, CMA) showed significant changes from pre- to postoperative $(p<0.01)$.

CONCLUSION: Intraoperative distraction, extension combined posterior decompression with use of plate-rod-screws occipitocervical fusion device is an effective method to treat $A A D, B I$ and $\mathrm{CHM}$ with syringomyelia.

KEYWORDS: Atlantoaxial dislocation, Basilar invagination, Chiari malformation, Syringomyelia, Occipitocervical fusion

\section{INTRODUCTION}

Craniovertebral junction (CVJ) malformations include bone, soft tissue, and neural structure malformations. AAD, BI and $\mathrm{AOL}$ are the most commonly encountered bone malformations, and $\mathrm{CHM}$ is the most common of the nervous structure malformations. The CVJ is an anatomical complex formed by the basis of the occipital bone, clivus, foramen magnum, and upper cervical vertebrae, their ligaments, and the vascular and nervous tissues passing through these bony structures (9). Because of the special relation of the bony, vascular and nervous elements within this region, any congenital malformation of one tissue may cause a wide spectrum of neurological deficit, especially the compression of medulla oblongata, which may lead to serious consequences.

Appropriate and timely diagnosis and treatment of these malformations are of great significance. However, there is still lack of an ideal method to cure all of these malformations. Anterior transoral decompression at the CVJ can occur in many types of pathology, including malformation (e.g., basilar invagination, atlas assimilation, os odontoideum, atlantoaxial 
fixed dislocation), tumor, trauma, chronicinflammatory diseases (most frequently rheumatoid arthritis), and osteomyelitis $(6,7$, 14, 31). Transoral approaches can directly access the lesion site, away from laterally placed neurovascular structures $(2,25)$. However, anterior transoral odontoid resection, combined with posterior decompression, instrumentation and craniocervical fusion in situ have a risk of predisposing the patient to cerebrospinal fluid leakage and neurological deficits $(5,20)$. For these reasons, a posterior approach to fixation has gained popularity and been demonstrated to be effective over other fixation $(1,4,16,17)$. More recently, it has been shown that distraction at the $\mathrm{C} 1 / \mathrm{C} 2$ joints leads to a possibility of reduction of $\mathrm{Bl}$ even in irreducible cases $(10,12,22)$.

We described here our occipitocervical fusion technique. Using posterior decompression of the atlas and foramen magnum followed by distraction at the occipital and C2 joints and extension at the head, we were able to achieve intraoperative restoration. We combined this approach with a plate-rod fixation system and occipital screws and C2/C3 lateral mass screws as well as iliac bone graft to accomplish reduction and fusion. We have found that this technique was an effective method to manage of reducible $A A D, B I$ and $C H M$ with syringomyelia.

\section{- MATERIAL and METHODS}

\section{Patients Population, Inclusion and Exclusion Criteria}

Forty-three patients who had AAD, BI, and CHM with syringomyelia underwent surgery in West China Hospital between January 2009 and January 2013. Their ages ranged from 23 years to 62 years (44.9). Of these patients, 40 (17 male and 23 female) were subsequently seen for a follow-up visit, which ranged from 12 to 48 months (mean, 25.211 .6 months). Patients that matched the following criteria were considered: (1) diagnosis of congenital reducible AAD (the atlantoaxial joint can be favorably reduced in extension or by traction), BI, and $\mathrm{CHM}$ with syringomyelia and ages more than 20 years old were considered; (2) complete clinical records and radiology documents (Dynamic plain x-rays, three-dimensional computed tomography (CT), magnetic resonance imaging (MRI)) were available both preoperatively and postoperatively; (3) all patients matched surgical indications (had obvious symptoms, ADI > $5 \mathrm{~mm}$, IOC > $3 \mathrm{~mm}$ ); (4) malformations were not caused by other non-congenital factors (e.g., rheumatoid arthritis, tumors, and trauma) and irreducible ADD (fails to reduce the atlantoaxial joint in extension or by traction) were excluded.

\section{Results Assess}

Nurick grading $(4,26)$ was defined as the following: Grade 0 , signs or symptoms of root involvement but without evidence of spinal cord disease; Grade 1, signs of spinal cord disease but no difficulty in walking; Grade 2, slight difficulty in walking that does not prevent full-time employment; Grade 3, difficulty in walking that prevented fulltime employment or the ability to do all housework, but not so severe as to require someone else's help to walk; Grade 4, able to walk only with someone else's help or with the aid of a frame; and Grade 5, chair bound or bedridden. The results were analyzed with IBM SPSS 19.0 and Student's t-test with statistical significance set at a $p$ value of 0.01 .

\section{Radiological Study}

Dynamic plain x-rays, three-dimensional CT, and MRI were conducted in all patients preoperatively and at follow-up. Forty patients' clinical records, photographs and follow-up documents were reviewed. ADI, IOC, SAC, and CMA were measured in our imaging system (Syngo Studio) as they are regarded as objective indices to judge the effects of surgery and classify the degree of restoration (Figure 1A,B). $\mathrm{X}$-ray and three-dimensional CT were used to diagnose the reducible reset and assess the bone fusion postoperatively. Lateral masses at $\mathrm{C} 2 / \mathrm{C} 3$ were also carefully assessed through preoperative three-dimensional CT. All patients underwent plain x-rays and three-dimensional CT scans to confirm the screw position and the extent of reduction within one week
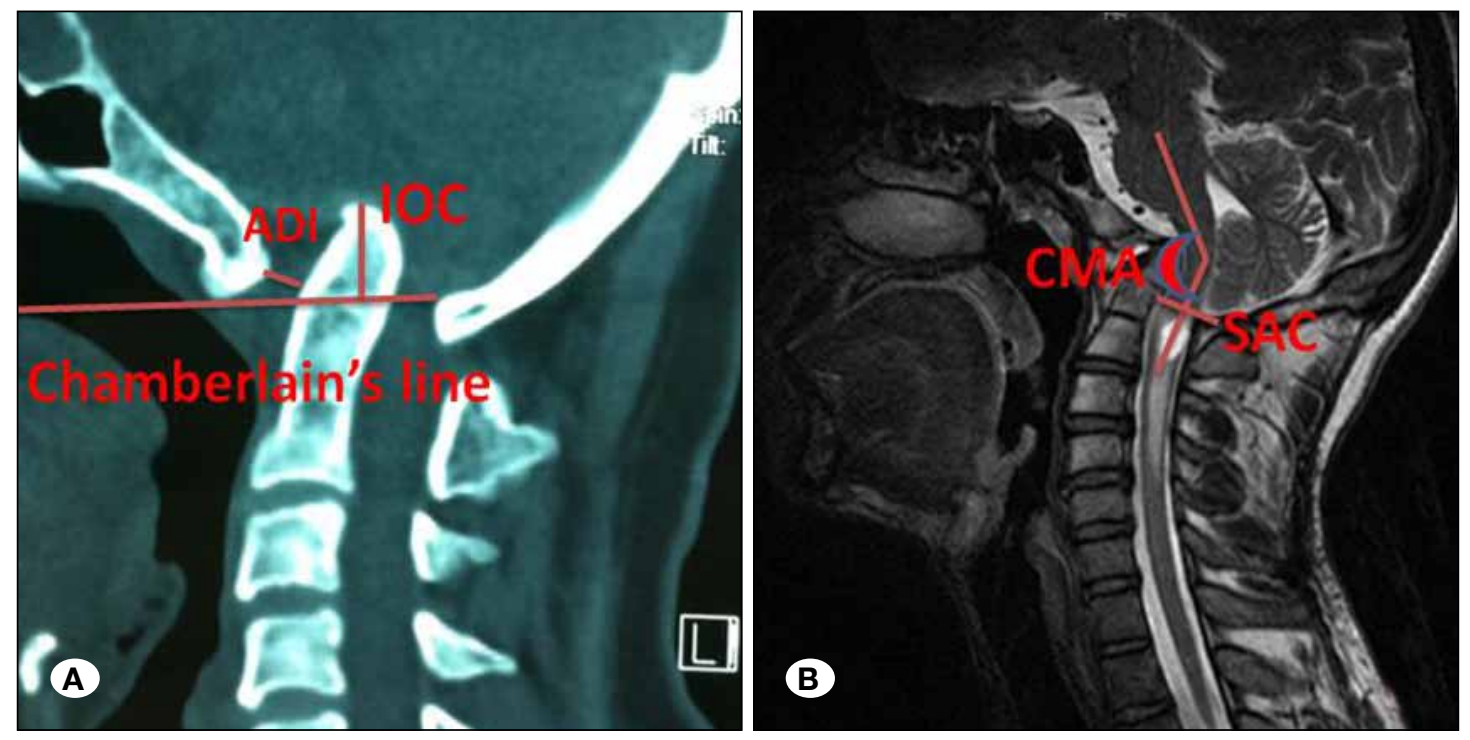

Figure 1:

A) Three-dimensional CT sagittal scan drawing the Chamberlain's line and measuring the atlantodental interval (ADI) and the interval between the odontoid and Chamberlain's line (IOC); and B) sagittal MRI scan measuring the space available for the spinal cord (SAC) and cervicomedullary angle (CMA). 
after the surgery. X-ray, three-dimensional CT and MRI were also performed three months after surgery to detect the extent of decompression of the spinal cord, the bone fusion and the decreased size of syringomyelia. These examinations were repeated at six months and one year postoperatively to further assess the bone fusion.

\section{Reducible and Restoration Classification}

We defined reducible as an ADI that changed in the flexion and extension X-ray scan and an atlantoaxial joint that could be favorably reduced in extension or by traction. Guided by the radiology findings, we classified three levels of restoration. Full restoration was defined as $A D I$ and $I O C$ reduced to normal (ADI $<3 \mathrm{~mm}, \mathrm{IOC}<3 \mathrm{~mm}$ ). Partial restoration meant that ADI and IOC were reduced and one of them had recovered to normal (postoperative ADI and IOC < preoperative ADI and $I O C, A D I<3 \mathrm{~mm}$ or $I O C<3 \mathrm{~mm})$. No restoration meant that $\mathrm{ADI}$ and $\mathrm{IOC}$ were not obviously reduced $(\mathrm{ADI}>3 \mathrm{~mm}$ and IOC $>3 \mathrm{~mm}$ ).

\section{Surgical Procedure}

All patients underwent surgery after finished the preoperative examinations. First, the patient was placed in the left lateral position following general anesthesia and intubation. Then two incision lines of occipitocervical (length of $8 \mathrm{~cm}$ ) and the right anterior superior iliac spine (length of $5 \mathrm{~cm}$ ) were marked. Second, the right iliac was exposed and $4 \mathrm{~cm} \times 3$ $\mathrm{cm}$ rectangular bone flap was excised; approximately $15 \mathrm{~g}$ of corticocancellous bone (obtained with osteotome) was used to bone graft (Figure 2A). Third, with use of a standard midline skin incision, the occipital squama and C2/C3 spinous process and bilateral lateral mass were exposed. The posterior arch of the atlas and part of the occipital bone $(2.5 \mathrm{~cm} \times 2 \mathrm{~cm})$ above the posterior edge of the foramen magnum (only splitting the outer dural layer for Chiari malformation) was cut. Fourth, the head was extended in a backwards manner to make the anterior arch of the atlas backwards and upward moving (Figure 3A), then fixed on one side with plate-rod-screws (Made in Beijing, China) (Figure 2A). The C2 lateral mass screws were implanted according to the preoperative three-dimensional
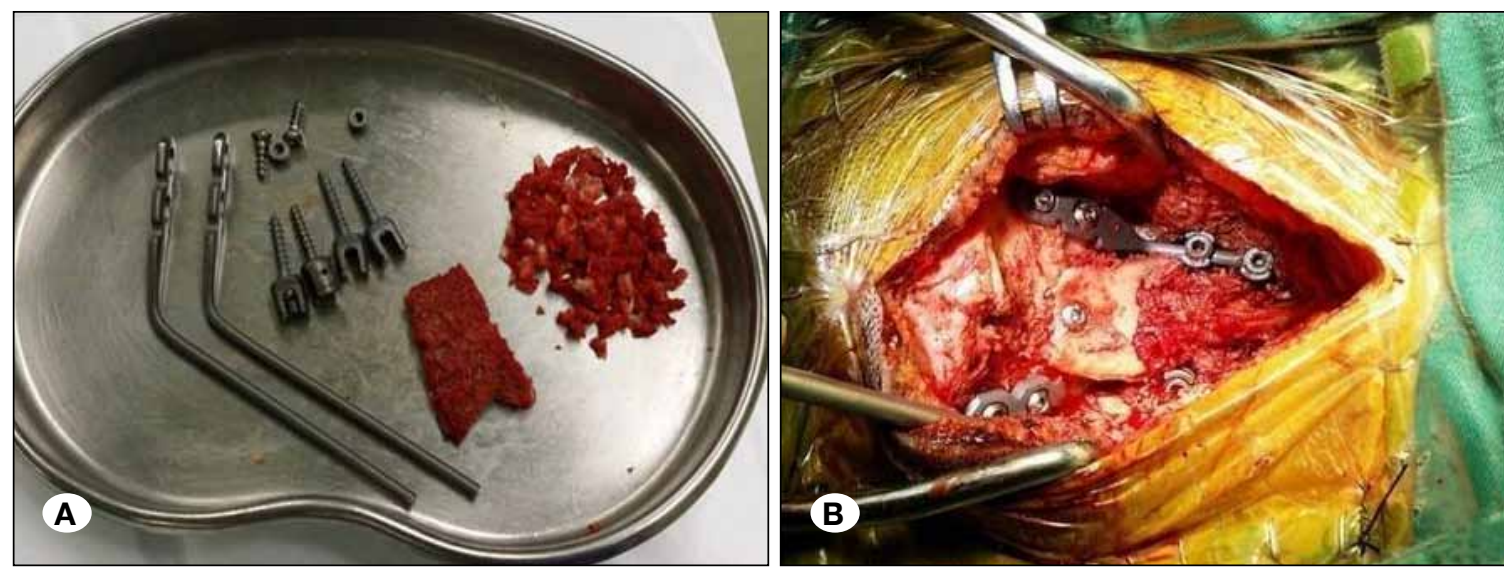

Figure 2:

Plate-rod-screws fixation device and autogenous iliac bone (A). The position of autogenous iliac bone graft (B).
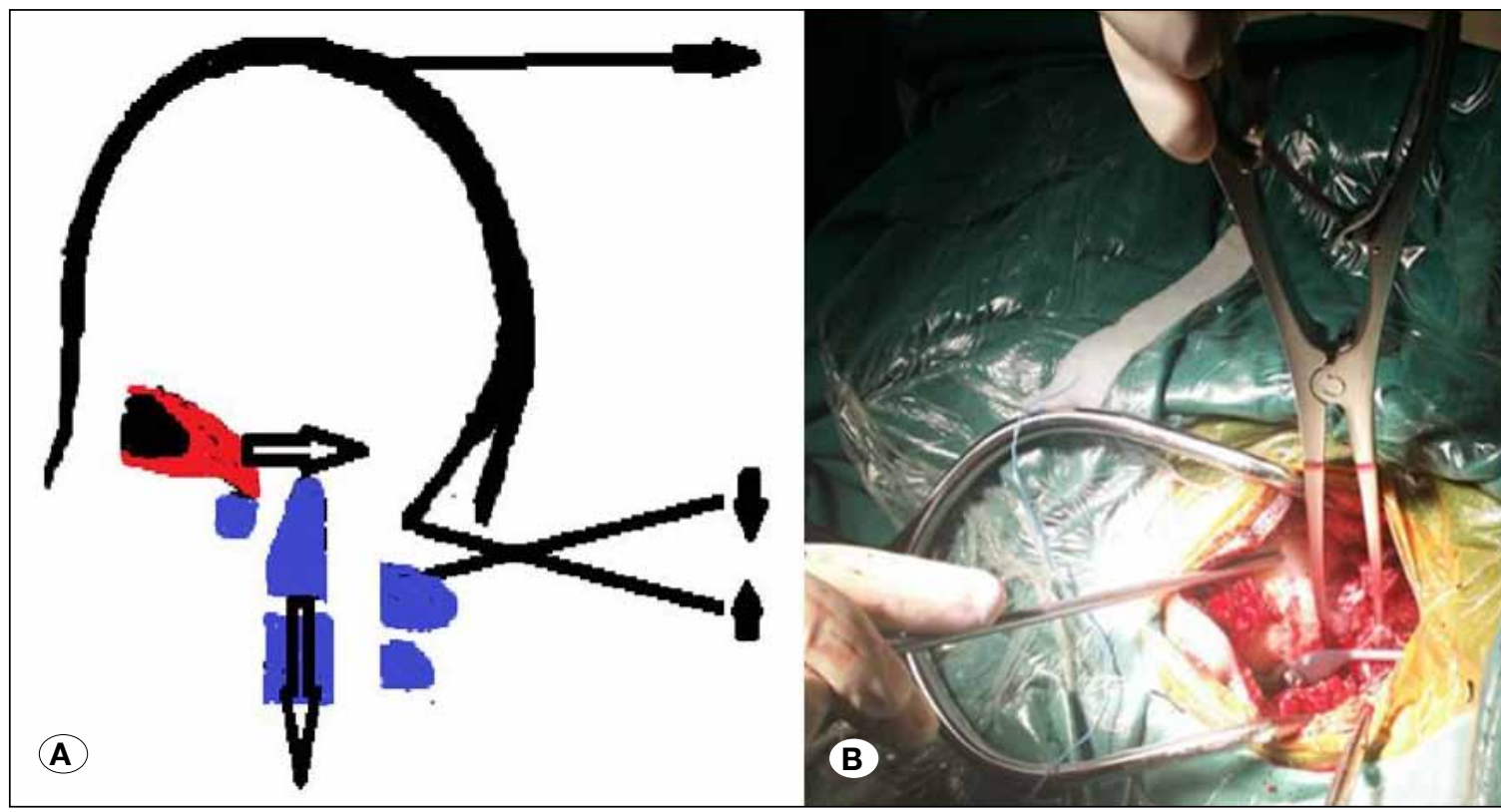

Figure 3: A) Schematic diagram of intraoperatively manipulated occipital and C2 distraction and head backwards extension to achieve restoration. B) Intraoperative occipital and C2 distraction by use of self-made device. 
CT. The inner lower edge of the inferior articular process was usually the entry point. The angle of screw trajectory was directed approximately $5^{\circ}$ interiorly and $55^{\circ}$ to $60^{\circ}$ superiorly. For C3 lateral mass screws, the entry point was located 1 $\mathrm{mm}$ medial to the mid-point of the lateral mass. The angle of screw trajectory was directed approximately $30^{\circ}$ laterally and superiorly (parallel to the facet joint) (19). Up and down distraction of occipital and axis are then performed using a self-made distraction system (Figure $3 \mathrm{~A}, \mathrm{~B}$ ) and fixed on the other side (the length of distraction was according to the preoperative imaging scan). Finally, the previously prepared rectangular bone flap was used to cover the foramen magnum (one screw fixing it to the occipital at one end and wedged with the spinous process of $\mathrm{C} 2$ ). A corticocancellous graft was harvested from the iliac crest to the margin of screws (Figure 2B). Every patient had to wear a cervical gear (hard collar) for three months to prevent the improper cervical movement that would result in fixation slipping.

\section{RESULTS}

\section{Surgical Outcomes}

Occipitocervical fusion was performed in all patients. The length of occipital screws varied from $8 \mathrm{~mm}$ to $12 \mathrm{~mm}$ (mean,

Table I: Clinical Profile of 43 Patients with Basilar Invagination, Atlantoaxial Dislocation and Chiari Malformation with Syringomyelia

\begin{tabular}{lc}
\hline Clinical features & No. of patients (\%) \\
\hline Limb weakness & $40(93)$ \\
Cervical motor limitation & $38(88)$ \\
Limb paresthesia & $42(98)$ \\
Cervical and shoulder pain & $25(58)$ \\
Ataxia & $18(42)$ \\
Dizziness & $10(23)$ \\
Respiratory difficulty & $3(7)$ \\
\hline
\end{tabular}

$10 \mathrm{~mm}$ ) and the length of $\mathrm{C} 2 / \mathrm{C} 3$ lateral mass screws varied from $14 \mathrm{~mm}$ to $18 \mathrm{~mm}$ (mean, $16 \mathrm{~mm}$ ). The diameter of the cortical screw was $3.5 \mathrm{~mm}$. The duration of the operation ranged from 90 minutes to 180 minutes (mean, 120), and blood loss ranged from 60 to $300 \mathrm{ml}$ (mean, 150). No patients died in the operation, but several surgery-related complications (two wound infections and one vertebral artery blockage) occurred after surgery. The mean hospitalization was 10 days.

\section{Clinical and Imaging Outcomes}

The details of the patients' preoperative symptoms are listed in Table I. Among forty-three patients, 40 (93\%) complained of limb weakness, 38 (88\%) presented with cervical motor limitation. 42 (98\%) experienced limb paresthesia, 25 (58\%) suffered from cervical and/or shoulder pain, and $3(7 \%)$ faced respiratory difficulties. Through the operation, thirty-six (90\%) patients' symptoms improved and four (10\%) patients stabilized. No patient became progressively worse. Mean Nurick grades from 3.1 0.7 preoperatively decreased to 1.6 0.6 postoperatively $(p<0.01)$. All patients had restoration; thirty $(75 \%)$ patients had full restoration and ten $(25 \%)$ had been partially reset. All radiology findings (ADI, IOC, SAC, CMA) showed significant changes from pre- to postoperative measures $(p<0.01)$ (Table II). Pre- and postoperative mean NGs of full and partial restoration were statistically significant. The size of syringomyelia had obviously diminished in 32 (80\%) (Figure 4A-D) patients and became stable in $8(20 \%)$ patients. The difference between pre- and postoperative mean NGs of these two groups were also statistically significant. Two patients developed wound infection and these wounds healed gradually over three weeks through the use of appropriate antibiotics along with meticulous dressings. One patient suffered respiratory difficulty preoperatively and relied on a breathing machine for one week before recovering autonomous respiration after surgery. Bone fusion was observed in all patients after one year following surgery. Only one patient's screws slipped because of improper cervical

Table II: The Statistical Difference Between Preoperative and Postoperative

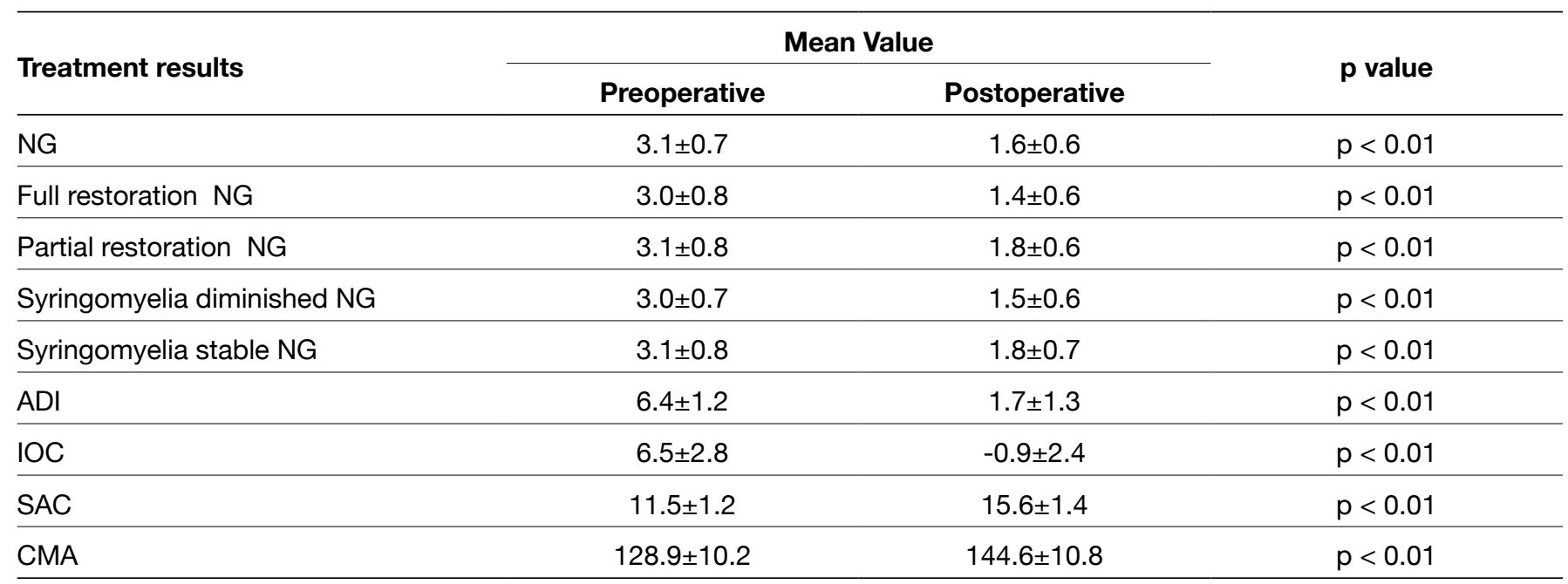

NG: Nurick grade, ADI: Atlantodental Interval, SAC: Space available for the spinal cord, CMA: Cervicomedullary angle, IOC: Interval between odontoid and Chamberlain's line. 

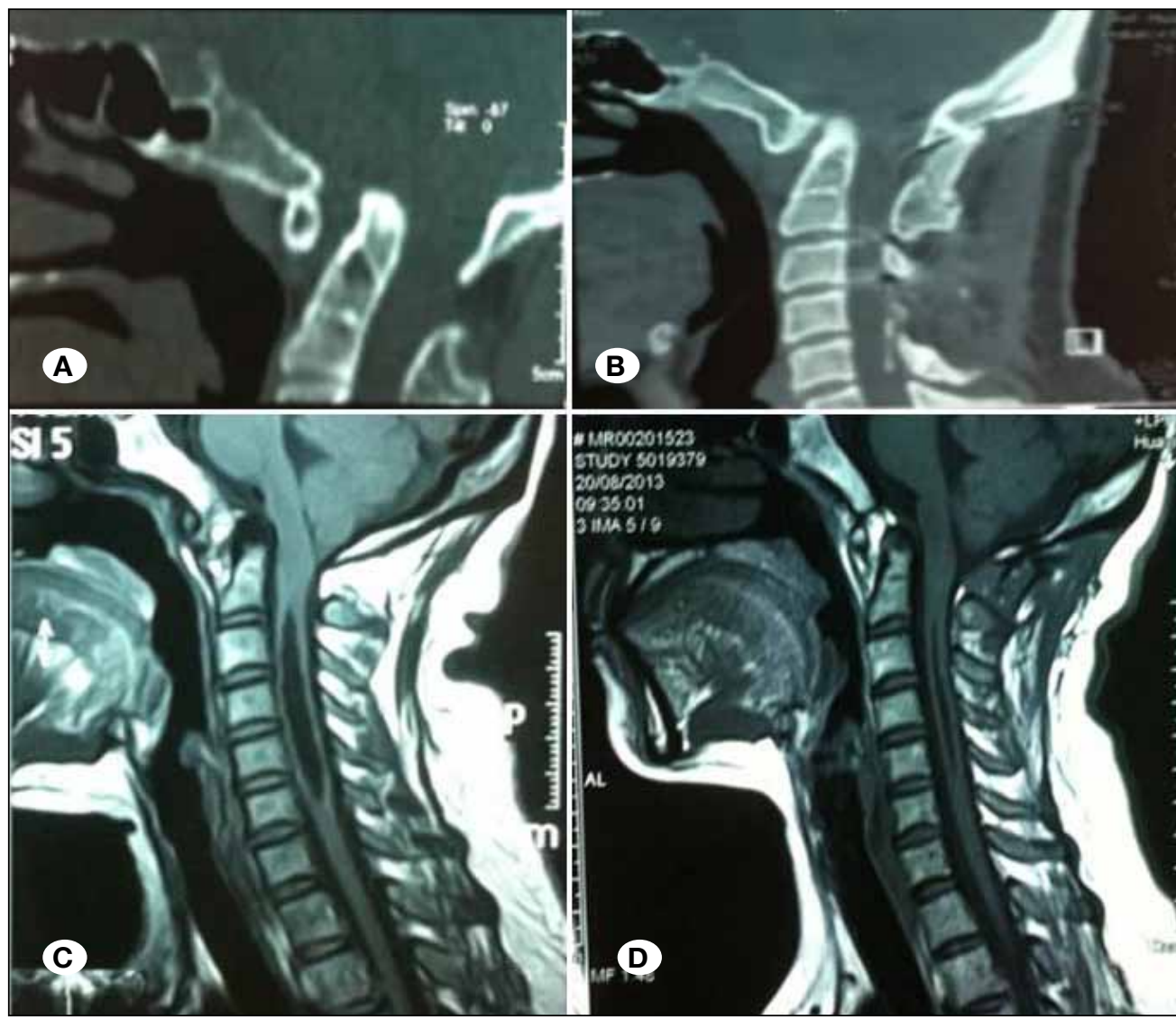

Figure 4: A 47-year-old female complained of lower limbs weakness for three years. Preoperative threedimensional CT scan (A) showed a diagnosis of atlantoaxial dislocation, basilar invagination, and mild Chiari malformation with syringomyelia was detected in MRI scan (C). Full restoration had achieved and the syringomyelia was obvious diminished in the postoperative imaging scan (B, D). activities and the fixation device had to be removed with a subsequent surgery.

\section{DISCUSSION}

There is no agreement among specialists regarding the appropriate surgical procedures that should be used for treating occipitocervical junction malformations, especially for AAD, $\mathrm{BI}$ and $\mathrm{CHM}$ with syringomyelia. Anterior transoral approach decompression or odontoid resection combined with posterior fixation are common techniques, but they have many drawbacks, including the deep and narrow surgical field, poor exposure of the odontoid, cerebrospinal fluid leakage, intracranial infection, high incidence of oropharyngeal dysfunction, risk of neurological deterioration, and even sudden death (23, $27,31)$. Moreover, transoral decompression itself may also worsen atlantoaxial stability, leading to increases in translation and range of motion (ROM) in all movements except axial rotation. Worsening of $\mathrm{Bl}$ as a result of transoral odontoidectomy has also been reported (11). In order to overcome these drawbacks, endoscopy-assisted transoral or transcervical procedures to treat occipitocervical junction diseases $(3,18$, $21,30)$ have been reported in the literature. Of course, possible cerebrospinal fluid leakage from aggressive pannus resection or dural tear, cervical instability, and vascular injury are also serious considerations (29).

Recently, several reports $(4,8,24,28)$ have claimed that posterior fixation is an effective method to treat $A A D$ and
BI. According to these reports, occipitocervical fusion and C1 and C2 fusion are two main fixations. Chandra et al. (4) reported that using an innovative method of distraction and spacer placement followed by compression and extension can reduce $A A D$ and $B I$. Goel et al. (15) used of the plate and screw method (C1/2 fusion) of fixation in the treatment of 160 patients with atlantoaxial instability and achieved good outcomes with low incidence of complications.

All of our patients presented $\mathrm{AAD}, \mathrm{BI}, \mathrm{AOL}$ and $\mathrm{CHM}$ with syringomyelia. Considering the reducible reset of the $A A D$ and accompaniment by $\mathrm{CHM}$, occipital to $\mathrm{C} 2 / \mathrm{C} 3$ fixed has been performed through the posterior approach. Why we are using of this method and not using C1/2 fusion? Some reasons are considered: (1) our patients were accompanied with $A D D, B I$, AOL and CHM with syringomyelia, whereas, Goel et al. (15) reported that their patients with atlantoaxial instability had no other deformities. $\mathrm{BI}$ and $\mathrm{CHM}$ with syringomyelia were not detected in their series. Therefore, Goel et al. (15) only used C1-2 lateral mass screws to treat of their patients. Additionally, Goel et al. (13) in 1995 reported the surgical treatment of five Chiari malformation associated with atlantoaxial dislocation. Occipitalized to C2/3 fusion was performed in two patients (these patients accompanied with $\mathrm{BI}, \mathrm{CHM}$ and syringomyelia) and C2-3 fusion was performed in the other patients. All of our patients suffered from $\mathrm{BI}$ and $\mathrm{CHM}$ with syringomyelia. The occipital and the posterior arch of atlas were cut in order to treat $\mathrm{CHM}$ associated with syringomyelia. Bl always leads 
to the embedding of the atlas or dysplasia of atlas which limits the use of $\mathrm{C} 1$ lateral mass screws and longer fusion was needed when there was some bone decompression in the craniovertebral junction area in order to preserve stability. Occipitalized to $\mathrm{C} 2 / 3$ fusion was performed just like Goel et al. (13) used in similar patients in 1995 (2). All of our patients were adults and no longer needed neck elongation and growth, which allowed for multilevel fixation. (3) In consideration of cost, relatively cheap plate-rod-screws (Made in Beijing, China) were used in our patients.

Combined with intraoperative distraction and extension, all patients achieved some degree of restoration. Most patients' clinical symptoms were dramatically improved and no patient's symptoms became worse after surgery. Changes pre- to postoperatively in mean NGs were statistically significant. Only 3 patients $(7.5 \%)$ experienced some minor complications, but all of them quickly recovered. Thirtytwo (80\%) patients' syringomyelia was decreased and 8 (20\%) were stabilized through purely epidural layer splitting followed by occipitocervical fusion. Not opening the dura can effectively avoid cerebrospinal fluid leakage; none of our patients suffered from this complication after surgery. Our aim was not to blindly pursue full restoration, but to improve symptoms while decreasing postoperative complications and surgical injury. Through a relative simple and safe surgical procedure, we were able to achieve satisfactory results. Our method of intraoperative restoration and fixed combination with posterior decompression not only increased SAC and CMA but also stabilized of occipitocervical junction region. It was a relatively safe and simple technique and yielded positive results, as expected.

There are several drawbacks of our method. First, the fusion of occipital to $\mathrm{C} 2 / \mathrm{C} 3$ limits cervical movements, especially rotary movement. However, most patients can drive a car and are less impacted in daily life by lumbar rotary compensation. Second, all the lateral mass screws were purchased without intraoperative fluoroscopy. Future refinements to our technique will be achieved through observing more patients and using longer follow-up periods to track the outcomes of our surgical method.

\section{CONCLUSION}

Surgical treatments of occipitocervical junction malformations still pose some challenges, even with our surgical technique. However, we are continuously refining the method and can report at this time that intraoperative distraction and extension in combination with posterior decompression and a plate-rodscrews occipitocervical fusion device is an effective method to treat $A A D, B I$ and $C H M$ with syringomyelia.

\section{ACKNOWLEDGEMENT}

Thanks to Professor Xiao for providing several images.

\section{REFERENCES}

1. Abumi K, Takada T, Shono Y, Kaneda K, Fujiya M: Posterior occipitocervical reconstruction using cervical pedicle screws and plate-rod systems. Spine (Phila Pa 1976) 24:1425-1434, 1999

2. Balasingam V, Anderson GJ, Gross ND, Cheng CM, Noguchi A, Dogan A, McMenomey SO, Delashaw JB, Andersen PE: Anatomical analysis of transoral surgical approaches to the clivus. J Neurosurg 105:301-308, 2006

3. Cavallo LM, Messina A, Cappabianca P, Esposito F, de Divitiis E, Gardner P, Tschabitscher M: Endoscopic endonasal surgery of the midline skull base: Anatomical study and clinical considerations. Neurosurg Focus 19: E2, 2005

4. Chandra PS, Kumar A, Chauhan A, Ansari A, Mishra NK, Sharma BS: Distraction, compression, and extension reduction of basilar invagination and atlantoaxial dislocation: A novel pilot technique. Neurosurgery 72:1040-1053, 2013

5. Crockard HA, Johnston F: Development of transoral approaches to lesions of the skull base and craniocervical junction. Neurosurgery Q 3:61-82, 1993

6. Di Lorenzo N: Craniocervical junction malformation treated by transoral approach. A survey of 25 cases with emphasis on postoperative instability and outcome. Acta Neurochir (Wien) 118:112-116, 1992

7. Di Lorenzo N: Transoral approach to extradural lesions of the lower clivus and upper cervical spine: An experience of 19 cases. Neurosurgery 24:37-42, 1989

8. Ding X, Abumi K, Ito M, Sudo H, Takahata M, Nagahama K, Iwata $A$ : A retrospective study of congenital osseous anomalies at the craniocervical junction treated by occipitocervical platerod systems. Eur Spine J 21:1580-1589, 2012

9. Erbengi A, Oge HK: Congenital malformations of the craniovertebral junction: Classification and surgical treatment. Acta Neurochir (Wien) 127:180-185, 1994

10. Goel A: Double insurance atlantoaxial fixation. Surg Neurol 67: 135-139, 2007

11. Goel A: Progressive basilar invagination after transoral odontoidectomy: Treatment by atlantoaxial facet distraction and craniovertebral realignment. Spine (Phila Pa 1976) 30:E551555, 2005

12. Goel A: Treatment of basilar invagination by atlantoaxial joint distraction and direct lateral mass fixation. J Neurosurg Spine 1:281-286, 2004

13. Goel A, Achawal S: Surgical treatment for Arnold Chiari malformation associated with atlantoaxial dislocation. $\mathrm{Br} \mathrm{J}$ Neurosurg 9:67-72, 1995

14. Goel A, Bhatjiwale M, Desai K: Basilar invagination: A study based on 190 surgically treated patients. J Neurosurg 88:962968, 1998

15. Goel A, Desai K, Muzumdar D: Atlantoaxial fixation using plate and screw method: A report of 160 treated patients. Neurosurgery 51:1351-1357, 2002

16. Grob D, Dvorak J, Panjabi MM, Antinnes JA: The role of plate and screw fixation in occipitocervical fusion in rheumatoid arthritis. Spine (Phila Pa 1976) 19:2545-2551, 1994 
17. Grob D, Schutz U, Plotz G: Occipitocervical fusion in patients with rheumatoid arthritis. Clin Orthop Relat Res 366: 46-53, 1999

18. Husain M, Rastogi M, Ojha BK, Chandra A, Jha DK: Endoscopic transoral surgery for craniovertebral junction anomalies. Technical note. J Neurosurg Spine 5:367-373, 2006

19. Inoue S, Moriyama T, Tachibana T, Okada F, Maruo K, Horinouchi Y, Yoshiya S: Cervical lateral mass screw fixation without fluoroscopic control: Analysis of risk factors for complications associated with screw insertion. Arch Orthop Trauma Surg 132:947-953, 2012

20. Jain VK, Behari S, Banerji D, Bhargava V, Chhabra DK: Transoral decompression for craniovertebral osseous anomalies: Perioperative management dilemmas. Neurol India 47:188195, 1999

21. Kassam AB, Snyderman C, Gardner P, Carrau R, Spiro R: The expanded endonasal approach: A fully endoscopic transnasal approach and resection of the odontoid process: Technical case report. Neurosurgery 57: E213, 2005

22. Landeiro JA, Boechat S, Christoph Dde H, Goncalves MB, Castro I, Lapenta MA, Ribeiro $\mathrm{CH}$ : Transoral approach to the craniovertebral junction. Arq Neuropsiquiatr 65:1166-1171, 2007

23. Limin L, Chunguang Z, Yueming S, Siqing H, Hao L, Quan G, Tao L, Jiancheng Z, Faming L: A posterolateral approach to occipitoatlantoaxial ventral lesions: A report of the long-term follow-up of 23 cases. J Spinal Disord Tech 26:281-290, 2013

24. Mingsheng T, Huimin W, Xin J, Ping Y, Hongyu W, Feng $Y$, Wu W, Guangbo Z: Screw fixation via diploic bone paralleling to occiput table: Anatomical analysis of a new technique and report of 11 cases. Eur Spine J 16:2225-2231, 2007
25. Mouchaty H, Perrini P, Conti R, Di Lorenzo N: Craniovertebral junction lesions: Our experience with the transoral surgical approach. Eur Spine J 18:13-19, 2009

26. Nurick S: The pathogenesis of the spinal cord disorder associated with cervical spondylosis. Brain 95:87-100, 1972

27. Perrini P, Benedetto N, Guidi E, Di Lorenzo N: Transoral approach and its superior extensions to the craniovertebral junction malformations: Surgical strategies and results. Neurosurgery 64:331-342, 2009

28. Stulik J, Vyskocil T, Sebesta P, Kryl J: Atlantoaxial fixation using the polyaxial screw-rod system. Eur Spine J 16:479484, 2007

29. Visocchi M: Advances in videoassisted anterior surgical approach to the craniovertebral junction. Adv Tech Stand Neurosurg 37:97-110, 2011

30. Wolinsky JP, Sciubba DM, Suk I, Gokaslan ZL: Endoscopic image-guided odontoidectomy for decompression of basilar invagination via a standard anterior cervical approach. Technical note. J Neurosurg Spine 6:184-191, 2007

31. Xia H, Yin Q, Ai F, Ma X, Wang J, Wu Z, Zhang K, Liu J, Xu J: Treatment of basilar invagination with atlantoaxial dislocation: Atlantoaxial joint distraction and fixation with transoral atlantoaxial reduction plate (TARP) without odontoidectomy. Eur Spine J 23:1648-1655, 2014 